\title{
Pesticide use and residue control in China
}

\author{
Fen Jin, Jing WANG*, Hua SHaO and Maojun JiN \\ Key Lab of Agro-product Quality and Safety, Institute of Quality Standards \& Testing Technology for Agro-products, \\ Chinese Academy of Agricultural Sciences, Beijing 100081, China
}

(Received February 5, 2010; Accepted March 8, 2010)

\begin{abstract}
Agricultural development continues to remain the most important objective in Chinese planning and policy. In the process of developing agriculture, pesticides have become an important tool to boost food production and fight diseases; however, immune suppression, hormone disruption, and cancer were seemingly related to pesticides according to a recent toxicological study. Therefore, pesticide use and control have become a significant issue in China, which is the largest producer of pesticides in the world. This paper reviews the application of pesticides in China and introduces countermeasures and proposals to control pesticide residues. (C) Pesticide Science Society of Japan
\end{abstract}

Keywords: Agriculture, Pesticide residues, Pesticide control in China.

\section{Introduction}

Pesticides are an important economic and effective method to increase the output and quality of agro-products in modern agriculture. According to the previous paper, ${ }^{1)}$ food supplies would immediately fall to 20 to $40 \%$ due to the ravages of pests without pesticides. As China is the largest country in Asia, and has a huge population, with a complicated climate and geographic environment covering cold, temperate and tropical zones, the situation of plant diseases and pests is severe. Moreover, China needs to support over $20 \%$ of the world's population using $10 \%$ of the total arable land in the world. Thus, the wide application of a variety of pesticides is necessary in China. However, with the progress of toxicology, there is growing worldwide concern about the ecological and human health risks of pesticides. That cancer and endocrinedisrupting effects might be related to pesticide exposure have been well documented, and the long-term fate of pesticide residue in the food chain and environment is also a concern from the viewpoint of risk assessment. Some pesticides, such as DDT, hexachlorocyclohexane (BHC) and dieldrin, have been banned for their persistence in developed countries since the 1980s, and China has also prohibited the production, use, and import and export of DDT, chlordane, BHC and mirex since 17 May, 2009. ${ }^{2)}$

\footnotetext{
* To whom correspondence should be addressed.

E-mail:w_jing2001@126.com

Published online April 30, 2010

(C) Pesticide Science Society of Japan
}

Agriculture is an important economic sector in China with 300 million farmers, which ranks first in worldwide farm output, primarily producing rice, wheat, potatoes, sorghum, peanuts, tea, millet, barley, cotton, oilseed, pork, and fish. Over the past three decades, agriculture output has quickly and steadily increased on the basis of agricultural reform and technological innovations. In the 1990s, China's agriculture entered a new stage of development, and the government has put forward unambiguous objectives of promoting high-yield, efficient, quality-oriented, eco-friendly and safety-driven agriculture to ensure agro-product quality and safety. The use, management and control of pesticides were highlighted. This paper addresses the pesticide use and residue control of agricultural products in China.

\section{Pesticide use in China}

The Chinese pesticide production industry started with the setting up of a DDT technical plant at Luzhong in Sichuan province in 1950 . In that time, only a few kinds of pesticides such as DDT, BHC and parathion could be manufactured. After nearly 50 years of development, China became the largest producer of pesticide in the world; more than 300 technical pesticides and 3000 pesticide formulations can be manufactured. ${ }^{3)}$ As shown in Fig. 1, the output of pesticides in China has appeared to increase steadily in the recent years; approximately 1.74 million tons of 300 different types of pesticides were produced in 2008, 2.8-fold than that in 2000 .

In addition, the pattern of pesticide product structure differs significantly in China. Organochlorine pesticides were the leading pesticide product from the 1950 s to 1980 s. And then, 


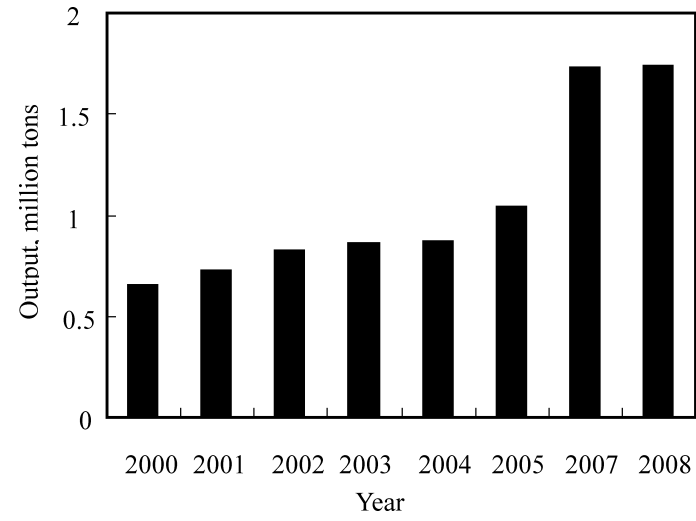

Fig. 1. Output of pesticides in China in recent years.

organophosphorus pesticides had become the most prominent pesticide, the output percentage of which was more than $70 \%$ of the total between 1980 and 2000. Currently, heterocyclic pesticides and bio-pesticides appear to be dominated, with a percentage of total output of approximately $60 \%$. As shown in Fig. 2, the proportion of insecticide output dropped from $61.3 \%$ in 2000 to $34.69 \%$ in 2008 , while the proportion of herbicides increased from $18 \%$ to $32.4 \%$. This change is a reflection of the transformation of the Chinese pesticide use pattern, in that highly toxic organophosphorus pesticides have been phased out of the market gradually with a strong global demand for herbicides, such as glyphosate, in the future.

Compared to the product structure pattern of pesticides in China, the pattern of pesticide consumption is slightly different. According to data from the National Agro-Tech Extension and Service Center (NATESC), of the total estimated 298 million $\mathrm{kg}$ of pesticides consumed, insecticides accounted for $46.98 \%$, followed by herbicides $(26.16 \%)$ and fungicides (25.49\%) in China in 2008. The average consumption of pesticides in China is $15 \mathrm{~kg} / \mathrm{ha}$, which is similar to the levels found in the Republic of Korea $(6.6 \mathrm{~kg} / \mathrm{ha})$ and Japan $(12.0$ $\mathrm{kg} / \mathrm{ha}$ ), but much higher than in any other Asian country, such as India $(0.5 \mathrm{~kg} / \mathrm{ha}){ }^{4)}$ Among the various pesticides used in

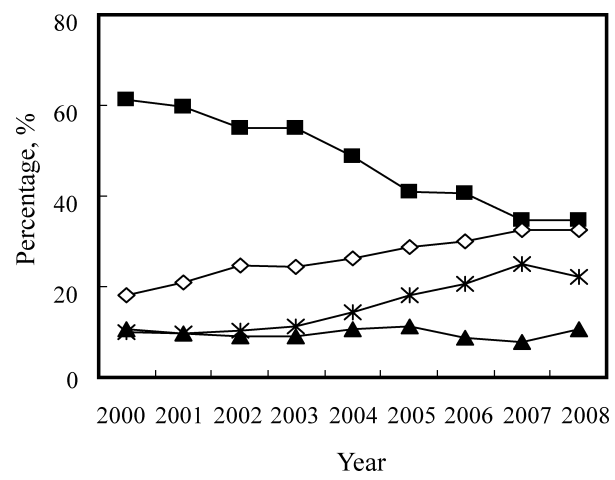

Fig. 2. Changes in proportion of different types of pesticides in recent years. (ם) Insecticide; $(\boldsymbol{\Delta})$ Fungicide; $(\diamond)$ Herbicide; $(\boldsymbol{X})$ Others.
Table 1. Thirteen Pesticides inspected in Plan of Action on Safe Agro-products in China

$\begin{array}{ll}\text { Methamidophos } & \text { Omethoate } \\ \text { Phorate } & \text { Chlorpyrifos } \\ \text { Parathion } & \text { Acephate } \\ \text { Parathion-methyl } & \text { Cypermethrin } \\ \text { Fenvalerate } & \text { Cyhalothrin } \\ \text { Deltamethrin } & \text { Chlorothalonil } \\ \text { Fenpropathrin } & \end{array}$

China, dichlorvos, acetochlor, copper sulfate, glyphosate and trichlorfon are consumed at more than 10 million kg annually. Phoxim, carbendazim, artrazine, butachlor, paraquat, chlorpyrifos, and acephate are all commonly consumed at between 5 and 10 million $\mathrm{kg}$ annually.

\section{Status of pesticide residues}

The Plan of Action on Safe Agro-products was launched in 4 pilot cities (Beijing, Tianjin, Shenzhen and Shanghai) in 2001 by the Ministry of Agriculture (MOA), and was extended and implemented in all large cities throughout the country. This action mainly focused on the control of 13 pesticide residues (Table 1) in vegetables, clenbuterol contamination in animal products, and chloramphenicol in aquatic products by routine inspection. The inspection project was designed by MOA, and then sampling and determination were carried out by several ministerial inspection centers, which are all accredited laboratories. At the same time, this was checked by other inspection centers to ensure accuracy if the result is higher than the MRLs. Finally, the results were issued to the public by the media, such as on the MOA website and Farmer's Daily.

Based on the inspection findings of pesticide residues in vegetables, the qualification rate on average has kept rising in China since 2003. As shown in Fig. 3, the average qualification rate of pesticide residues in vegetables was $96.4 \%$ in

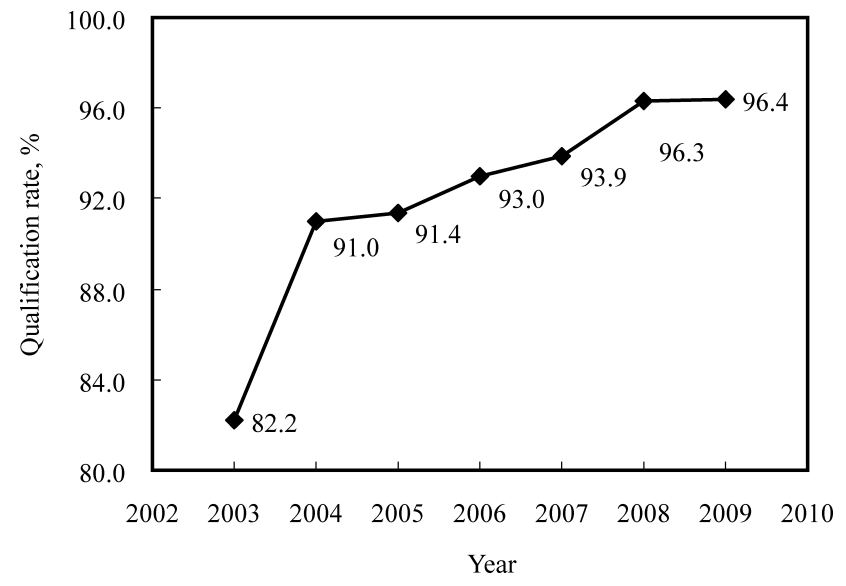

Fig. 3. Results of routine inspection of vegetables from 2003 to 2009 in China. 
2009, which was increased 14.2 percents to that in 2003. And these average qualification rates were calculated by the residue data from different links in food circulation. For example, according to residue data from January and April 2007, the qualification rate was $93.9 \%$ on average in 2007 , derived from $96.7 \%$ from production bases, $92.5 \%$ from farm produce markets, $93.7 \%$ from wholesale markets, and $91.7 \%$ from supermarkets. ${ }^{6}$ )

However, to the best of our knowledge, the object of the Action Plan on Safe Agro-products was to control the illegal use of highly toxic pesticides as well as residues in excess of limits. Therefore, the scope of the pesticides in the current inspection is relatively lacking, and data on other pesticides not listed in the inspection plan are only available in research papers or others in China.

\section{Pesticide control}

In recent years, several measures, including legislation, regulation, agricultural standardization, accredited agro-products, and education, have been adopted to control pesticide residues in China.

\section{Laws and regulations}

The Chinese government has promulgated a number of laws and regulations targeting agro-product quality and safety standards. As shown in Table 2, a legal framework for agro-product quality and safety is being established step by step in China. For example, the Law of the People's Republic of China on Agricultural Product Quality Safety (2006) and the Food Safety Laws of the People's Republic of China (2009) have come into force, indicating the new development of legislation in food safety. To enforce the Law of the People's Republic of China on Agricultural Product Quality Safety
(2006), the government has organized the drafting of Administrative Measures for the Safety of Places of Agricultural Products (2006) and Administrative Measures on Agro-food Package and Labeling (2006). Furthermore, the MOA named 2008 as the year of administration of pesticide registration, in order to promote the implementation of laws and regulations on pesticide registration. Intensive rectification campaigns on the quality and safety of agro-products were carried out by the MOA in 2009 in accordance with the law, and 2009 was named the law enforcement year.

\section{Agricultural standard system}

In view of the WTO and Sanitary and Phytosanitary (SPS) agreements, the government adopted a series of actions to establish a standard system. The MOA organized the formulation of 3480 agriculture profession standards and guided the local authorities in formulating over 8000 local standards by the end of 2007 , of which $69 \%$ of standards were formulated after 2000. These standards, extending to crop, livestock, and aquatic products, have formed a system of agricultural standards pillared by national and sectional standards, supported by local standards and supplemented by company standards. Although the progress in standardization was obvious, pesticide maximum residue limits (MRLs) were relatively scarce in China. According to the report of Ma et al., only 480 MRLs involved 136 pesticides were formulated in China by the end of $2007,{ }^{7}$ ) significantly lower than that in CAC, the EU and America.

In addition, demonstration zones were established on country, province and county levels, which covered an area of over 33 million ha. Agricultural standardization has contributed to the transformation of production practices and promotion of the quality and safety of agro-products.

Table 2. Legal framework for agro-product quality and safety in China

\author{
National law or regularity \\ Law of the People's Republic of China on Agricultural Product Quality Safety (2006), \\ Food Safety Laws of the People's Republic of China (2009), \\ Agriculture Law of the People's Republic of China (1993) \\ Ministerial regulation \\ Management Measures for the Production of Pesticides (2004), \\ Regulations on the Management of Pesticides (2007), \\ Measures for the Administration of Pesticide Labels and Manuals (2007), \\ Decision on Amending the Measures for Implementing the Regulation on Pesticide Administration (2007), \\ Data Requirements of the Pesticide Registration (2007) \\ Administrative Measures for the Safety of Places of Agricultural Products (2006) \\ Administrative Measures on Agri-products Package and Labeling (2006), \\ Decision of the Ministry of Agriculture on Revising the Agricultural Administrative Regulations \\ and Regulatory Documents \\ Local regulation \\ Administrative Regulation of Quality and Safety of Agricultural Products in Hunan Province \\ Provisions on the Supervision over and Administration of the Quality Safety of Export Agricultural \\ Products in Shandong Province
}


Table 3. Standardized methods for pesticide multi-residues in China

\begin{tabular}{|c|c|c|c|}
\hline Objective samples & Standard No. & Pesticides & Methods \\
\hline Fruits and vegetables & GB/T 20769-2008 & 450 pesticides & GC-MS and LC-MS-MS \\
\hline Grains & GB/T 20770-2008 & 486 pesticides and related chemicals & LC-MS-MS \\
\hline Honey & GB/T 20771-2008 & 486 pesticides and related chemicals & LC-MS-MS \\
\hline Animal muscles & GB/T 20772-2008 & 461 pesticides and related chemicals & LC-MS-MS \\
\hline Mulberry twig, honeysuckle, & GB/T 23200-2008 & 488 pesticides and related chemicals & GC-MS \\
\hline $\begin{array}{l}\text { barbary wolfberry fruit } \\
\text { and lotus leaf }\end{array}$ & GB/T 23201-2008 & 413 pesticides and related chemic als & LC-MS-MS \\
\hline Mushrooms & GB/T 23202-2008 & 440 pesticides and related chemicals & LC-MS-MS \\
\hline Mushrooms & GB/T 23216-2008 & 503 pesticides and related chemicals & GC-MS \\
\hline \multirow[t]{2}{*}{ Teas } & GB/T 23204-2008 & 519 pesticides and related chemicals & GC-MS \\
\hline & GB/T 23205-2008 & 448 pesticides and related chemicals residues & LC-MS-MS \\
\hline $\begin{array}{l}\text { Fruit juice, vegetable juice } \\
\text { and fruit wine }\end{array}$ & GB/T 23206-2008 & 512 pesticides and related chemicals residues & LC-MS-MS \\
\hline \multirow[t]{2}{*}{ Fugu, eel and prawn } & GB/T 23207-2008 & 485 pesticides and related chemicals & GC-MS \\
\hline & GB/T 23208-2008 & 450 pesticides and related chemicals & LC-MS-MS \\
\hline \multirow[t]{2}{*}{ Milk and milk powder } & GB/T 23210-2008 & 511 pesticides and related chemicals & GC-MS \\
\hline & GB/T 23211-2008 & 493 pesticides and related chemicals residues & LC-MS-MS \\
\hline Drinking water & GB/T 23214-2008 & 450 pesticides and related chemicals & LC-MS-MS \\
\hline Vegetables and fruits & NY/T 761-2008 & $\begin{array}{l}\text { Carbamate (10), organophosphorus (54), } \\
\text { organchlorine (29), and pyrethroid (12) } \\
\text { pesticides }\end{array}$ & GC, LC \\
\hline
\end{tabular}

\section{Inspection system}

To improve the capacity for monitoring pesticide residues in agro-products, the Chinese government has made great efforts in recent years. The first step was to establish well-equipped ministerial inspection centers in 1988, 1991, 1998, 2003 and 2005, respectively. By 2006, 323 national (ministerial) inspection centers, and 1780 provincial, prefectural and county inspection agencies should be established. The second step was to invest 6 billion Yuan to upgrade the conditions of these inspection centers and stations at provincial, municipal and county levels in 2005. Advanced instruments, such as LCMS/MS, GC-MS, and even UPLC-MS/MS, were equipped in inspection centers at different levels. The final step was to carry out routine inspections in 37 cities across the whole country from 2003.

The most important part of the inspection system is the analytical method. In China, centralized determination of pesticide residues is difficult because of individual farming patterns. In addition, the validation of analytical methods requires many human and material resources; therefore, screening methods combined with validation methods are established as the Chinese inspection method system.

The enzyme inhibition method is an important screening method that is only applied to detect organophosphate and carbamate in vegetables and tea in China. Currently, there are many screening test products using enzyme inhibition on the market, including test paper, test regents and a rapid determination meter photoelectricity system, some of which have become national or ministerial standard methods, such as GB/T 18625-2002, ${ }^{8)} \mathrm{GB} / \mathrm{T} 18630-2002^{9)}$ and NY/T 448-2001. ${ }^{10)} \mathrm{Al}-$ though these methods are convenient and cheap, they have low sensitivity and false positive results frequently occurred. Thus, they are only used in the agro-product wholesale market. The enzyme-linked immunosorbent assay (ELISA) is another screening method, which is more widely used to determine veterinary medicine and biological toxins than pesticides in China. To our knowledge, there is only one standard (SN/T 2094-2008) for ELISA to determine pesticides ( $\alpha$-endosulfan and $\beta$-endosulfan) in China. ${ }^{11)}$

The validation method is generally referred to as the chromatography method, which provides higher sensitivity and selectivity, and gives quantitative results on multi-residues. With the improvement of mass techniques, the GC-MS/MS method combined LC-MS/MS method can determine nearly all registered pesticides. As shown in Table 3, there are many standards for multi-residue determination in China; for example, GB/T 20769-2008 is the determination method for 450 pesticide residues in fruits and vegetables by $\mathrm{LC}-\mathrm{MS} / \mathrm{MS}{ }^{12)}$ It should be noted that most method standards are recommended over compulsory standards, which can be freely se- 
lected for daily inspection, with one exception; NY/T 761$2008^{13)}$ is the only method adopted by MOA in the Action Plan on Safe Agro-products.

\section{Certification of agro-products}

In order to minimize the risk and health effect of pesticides, the growth of certificated agro-products, such as safe agroproducts, green food and organic agro-products is an important measure. To our knowledge, about $90 \%$ of exported agroproducts are safe, green and organic agro-products. In total, 600 organic agro-product label holders have been certified by the China Organic Food Certification Center (COFCC) for 2647 products, with 19.56 million tons from 3 million ha. of certified production locations. Although the proportion of certificated agro-products is small for their relatively high price in domestic markets, we need to develop this process further.

\section{Conclusions}

In the past few years, the government has strived hard to solve the various food safety problems caused by the increasing use of pesticides; however, there is a long way to go, and it is a very demanding to establish and improve the agro-product quality and safety system; therefore, we need to promote agriculture science research and the education of farmers.

\section{References}

1) Q. Shi and S. SUN: Shanxi Agri. Econo. 2, 35-37 (2000) (in Chinese).

2) http://www.china-pops.org/zcfg/dtzc/200906/t20090602_11157. $\mathrm{htm} /$ Accessed 2 Jun., 2009

3) http://202.127.45.50/ztzl/xzgnylsn/cjyhg/t20090921_1354798. $\mathrm{htm} /$ Accessed 21 Sep., 2009

4) P. C. Abhilash and N. Singh: J. Hazard. Mater. 165, 1-12 (2009)

5) http://ampcn.com/news/detail/34814.asp/Accessed 27 Nov.,
2007

6) http://www.china.com.cn/policy/txt/2007-09/24/content_ 8940951.htm/Accessed 24 Sep., 2007

7) A. Ma: Food \& Nutr. Chin. 1, 12-14 (2008) (in Chinese).

8) State General Administration of the People's Republic of China for Quality Supervision and Inspection and Quarantine: "Method for simple determination of organophosphorus and carbamate pesticide residues in tea, Enzyme inhibition method GB/T 18625-2002", Chinese Standard Press, Beijing, 2002 (in Chinese).

9) State General Administration of the People's Republic of China for Quality Supervision and Inspection and Quarantine: "Method for simple determination of organophosphorus and carbamate pesticide residues in vegetables (enzyme inhibition method) GB/T 18630-2002", Chinese Standard Press, Beijing, 2002 (in Chinese)

10) The Ministry of Agriculture of the People's Republic of China: "Rapid bioassay of organophosphate and carbamate pesticide residues in vegetables NY/T 448-2001", Chinese Standard Press, Beijing, 2001 (in Chinese).

11) State General Administration of the People's Republic of China for Quality Supervision and Inspection and Quarantine: "Determination of $\alpha$-endosulfan and $\beta$-endosulfan residues in foodstuff for export and import (Enzyme linked immunosorbent assay method) SN/T 2094-2008", Chinese Standard Press, Beijing, 2008.

12) State General Administration of the People's Republic of China for Quality Supervision and Inspection and Quarantine: "Method for determination of 450 pesticides residues in fruits and vegetables GC-MS and LC-MS-MS GB/T 20769-2008" Chinese Standard Press, Beijing, 2008 (in Chinese).

13) The Ministry of Agriculture of the People's Republic of China: "Pesticide multiresidue screen methods for determination of organophosphorus pesticides, organochlorine pesticides, pyrethroid pesticides and carbamate pesticides in vegetables and fruits NY/T761-2008", Chinese Standard Press, Beijing, 2008 (in Chinese). 